\title{
La autonomía de la función electoral desafiada por la jurisdicción constitucional: concreción en Costa Rica de una problemática latinoamericana del siglo XXI*
}

Nota del Consejo Editorial

DOI 10.35242/RDE_2019_27_2

Recepción: 1 de octubre de 2018.

Revisión, corrección y aprobación: 7 de noviembre de 2018.

Resumen: A partir de la exposición de la institucionalidad electoral latinoamericana en donde se distinguen dos fórmulas: la unificada, que concentra en un solo organismo autónomo la administración y la jurisdicción electoral; y la diversificada, que supone una instancia de administración electoral orgánicamente separada de una jurisdicción electoral especializada, se analiza la institucionalidad electoral en Costa Rica, su autonomía y el deslinde de competencias entre lo constitucional y lo electoral, en este caso en particular.

Palabras clave: Jurisdicción electoral / Administración electoral / Organización electoral / Justicia electoral / Control jurisdiccional / Conflicto de competencias / Interpretación constitucional / Costa Rica.

Abstract: It analyzes the electoral institution in Costa Rica, its autonomy and the boundary of powers between constitutional and electoral matters in this particular case by means of presenting Latin American, electoral institutions in which two formulas can be distinguished: the unified formula which concentrates in one autonomous body the electoral administration and jurisdiction; and the diversified formula which entails an electoral administration body organically separated from a specialized electoral jurisdiction.

Key Words: Electoral jurisdiction / Electoral administration / Electoral organization / Electoral Justice / Jurisdictional control / Conflict of powers / Constitutional interpretation / Costa Rica.

\footnotetext{
* Este artículo tiene como base la conferencia que, con el mismo título, impartió su autor el 18 de octubre de 2018, en el Primer Congreso Internacional de Justicia Electoral y Valores Democráticos, celebrado en Santo Domingo, República Dominicana.

** Costarricense, abogado, correo Isobrado@tse.go.cr. Licenciado y doctor en Derecho por la Universidad de Costa Rica y la Universidad Complutense de Madrid, respectivamente. Magistrado propietario del TSE a partir de 1999. Ocupa la presidencia del organismo electoral costarricense desde el año 2007 y es el director de su Revista de Derecho Electoral. Con anterioridad a su ingreso al TSE, había desempeñado otros cargos públicos en la Procuraduría General de la Republica y en el Ministerio de la Presidencia. Tiene más de tres décadas de ser profesor de Derecho Constitucional en la Universidad de Costa Rica y desde 1993 coordina la respectiva Cátedra de su Facultad de Derecho. Autor de los libros La justicia electoral en Costa Rica (San José: IJSA, 2005), Democratización interna de los partidos políticos en Costa Rica (San José: FLACSO, 2007), Elecciones y democracia (San José: IFED/KAS, 2014), Para entender el Tribunal Supremo de Elecciones y la justicia electoral (San José: IFED/KAS, 2018) y de numerosos artículos en revistas especializadas.
} 


\section{DERECHO ELECTORAL}

\section{INTRODUCCIÓN}

Newton postulaba, en su tercera ley del movimiento, que cuando un cuerpo ejerce una fuerza sobre otro, este ejerce sobre el primero una fuerza igual y de sentido opuesto.

Me sirvo de esta regla de la física a modo de metáfora de lo sucedido a los organismos electorales latinoamericanos en su historia reciente.

A partir de la década de los setenta, con la tercera ola democrática, la mayoría de esos organismos enfrentaron la necesidad de consolidar una institucionalidad con capacidad para organizar y juzgar procesos electorales confiables y legítimos (Picado y Aguilar, 2012, p. 117).

Se trata de una evolución cuyos positivos resultados son plenamente reconocibles a finales del siglo XX; época en que esa institucionalidad inicia una etapa de expansión de sus competencias y diversificación de su agenda. La jurisprudencia, las decisiones administrativas de los organismos electorales y las reformas legales que impulsan denotan un interés regional convergente en temas como la democracia interna de los partidos, el control de su financiamiento, la equidad de las elecciones y la desigualdad de género en la competencia política. Interés que se traduce, en la primera década de este siglo, en crecientes atribuciones de la institucionalidad electoral para incursionar en esos ámbitos, como también en la formación política y ciudadana, otrora espacio reservado a las agrupaciones políticas.

Era de esperar que esa acción provocara una reacción. Como bien lo apunta el maestro Nohlen:

...la enorme ampliación de las competencias de los órganos de administración y jurisdicción electoral... hace sugestivo tratar de influir en sus decisiones, contraponiéndose así al propio fortalecimiento de la justicia electoral en el sentido de su mayor independencia y autonomía. Cuando ella no solo es responsable de organizar y controlar el proceso electoral conforme a parámetros del Estado de derecho sino incide también en los partidos políticos, en su vida interna, en su financiación y en las campañas electorales, entonces toma decisiones en un campo políticamente muy sensible ... No cabe duda que el mayor desafío de la justicia electoral en América Latina consiste en el mantenimiento de su independencia frente al poder político que 


\section{DERECHO ELECTORAL}

en algunos países de América Latina ya no existe. Se puede decir que haber conseguido esta independencia en casi todos los países de la región durante los años noventa, ha sido la precondición necesaria para el desempeño regional positivo de las instituciones de la justicia electoral. Sin embargo, este logro no fue acompañado de la convicción realmente generalizada de que los actores políticos estén subordinados a las reglas. Sigue vigente la idea de que las reglas son disponibles y adaptables a los intereses de los actores políticos. (2017, p. 15).

En este orden de ideas no sorprende que, aún en los primeros años del siglo XXI, los organismos electorales seguían percibiendo a esos actores políticos como la principal amenaza a su autonomía, que podía concretarse de muy diversas formas: cuotas partidarias en el nombramiento de magistrados electorales, estrangulamiento presupuestario, modificaciones legales acomodaticias, etc.

Esta percepción tiende a variar en la presente década. No es casual que en el congreso del Consejo Europeo de Investigaciones Sociales en América Latina (CEISAL) de 2016, celebrado en Salamanca, las cuatro autoridades electorales latinoamericanas que coincidimos en una mesa de trabajo unánimemente reenfocábamos la cuestión, dirigiendo la mirada hacia la jurisdicción constitucional de nuestros países.

Y es que no son escasos los ejemplos regionales que evidencian el deseo de muchos jueces constitucionales de influir en el ámbito electoral; predisposición que ha supuesto, a juicio de sus pares electorales, ir más allá de las delimitaciones competenciales constitucionalmente previstas, en demérito de la actuación autónoma de los organismos electorales.

¿Qué hay detrás de ello? Aunque un cúmulo de factores podría estar involucrado y no obstante la diversidad de circunstancias que rodean cada caso particular, me aventuro a decir que ahora son menos probables los manotazos directos de los poderes Ejecutivo y Legislativo contra las autoridades electorales. No solo causan indignación popular, sino que hoy la justicia constitucional actúa como un resguardo y remedio efectivo. No obstante, conjurado en cierta medida ese riesgo, aparece uno distinto: el paradójico desencuentro entre las jurisdicciones constitucional y electoral.

Puestos a hipotetizar, ese desencuentro obedecería a circunstancias más ligadas al afán de poder y protagonismo de los seres humanos y sus 


\section{DERECHO EIECTORAL}

instituciones. Sin embargo, también estaría en juego un emergente activismo judicial, alentado por la crisis de la representación política que se agudizó en la América Latina de los tiempos bolivarianos. En el peor de los escenarios, algunos jueces de la región (electorales o constitucionales) podrían estar siendo influidos por los actores políticos y sirviendo de vehículo a sus intereses.

Tengamos en cuenta, a propósito de esto, el desencanto con la democracia que sucede a esa tercera ola. La regularización constitucional no condujo a una mayor calidad de vida de sus habitantes. Permanecimos en la triste condición de sobresalir en los índices mundiales de desigualdad, violencia y corrupción, con el consecuente agravamiento de la desconfianza en las clases políticas, los partidos y los parlamentos.

Ese contexto podría estar seduciendo a los jueces de ambos bandos a ocupar esos campos vacíos de credibilidad ciudadana. A posicionarse como decisores políticos y no como simples contralores de los representantes populares, a contrapelo de la lógica democrática, que les encomienda a estos últimos discernir la voluntad general. En palabras del mismo Nohlen (2017, pp. 16-17), este abandono del selfrestraint judicial se inscribe en un fenómeno de creciente judicialización de la política, en donde los tribunales constitucionales y electorales "a veces se portan como actores opuestos". Judicialización de la política que, en la cultura regional, "tiende a coincidir... dialécticamente con mayor politización de la justicia. Esta interrelación produce una creciente y contradictoria diversidad de normas y su interpretación se realiza acorde con la coyuntura política" (Nohlen (2017, pp. 16-17).

La hostilidad entre jueces electorales y constitucionales tiende entonces a traducirse en un inapropiado pulso en la cúspide del Estado, parcialmente cedida -en repliegue- por una clase política debilitada.

Para comprender este pulso, en lo que resta de esta exposición analizaré la autonomía de los organismos electorales, el deslinde de competencias entre esas jurisdicciones, su desencuentro en Costa Rica y, finalmente, plantearé una reflexión sobre el particular. 


\section{DERECHO ELECTORAL}

\section{EL MODELO LATINOAMERICANO DE INSTITUCIONALIDAD ELECTORAL Y LA AUTONOMÍA DE LA JURISDICCIÓN ELECTORAL}

América Latina exhibe un modelo original de organización electoral, fruto del deseo (históricamente comprensible) de apartar al Poder Ejecutivo de la organización de las elecciones y al Legislativo de su calificación. Se caracteriza por la existencia de organismos permanentes y especializados que gestionan autónomamente la función electoral y, en ciertos casos, también el registro civil. Se trata de órganos constitucionales, es decir, previstos y regulados directamente por las respectivas constituciones. Algunas de estas refuerzan su connatural independencia orgánica reconociendo a esos organismos como "Poder Electoral" -Nicaragua y Venezuela- (con lo que no solo se rompe la tradicional visión tripartita de las funciones del Estado, sino que se amplía la tríada clásica de sus poderes) o atribuyéndoles expresamente "el rango e independencia de los Poderes del Estado" -Costa Rica- (Sobrado, 2006, p. 20).

De acuerdo con Orozco este modelo puede considerarse:

...como una de las aportaciones más significativas de la región a la ciencia política y al derecho electoral, al haberse constituido en un factor importante para los recientes procesos de redemocratización y consolidación democrática en América Latina, así como a la vigencia del Estado de derecho y a la consiguiente solución de los conflictos electorales por vías institucionales. (2001, p. 47).

No obstante, podemos distinguir dos fórmulas diferenciadas de ese modelo regional común: la unificada, que concentra en un solo organismo autónomo la administración y la jurisdicción electorales (como sucede en todos los países centroamericanos y algunos de Suramérica), de la diversificada, que supone una instancia de administración electoral orgánicamente separada de una jurisdicción electoral especializada, ya sea autónoma (como el Jurado Nacional de Elecciones de Perú) o incrustada en el Poder Judicial (como el Tribunal Electoral del Poder Judicial de la Federación de México).

La creación de la jurisdicción electoral fue la manera en que América Latina superó el contencioso clásico o político que predominara en el siglo XIX. Supuso investir a jueces independientes y profesionales (ubicados dentro o 


\section{DERECHO ELECTORAL}

fuera de la esfera judicial) con la responsabilidad de arbitrar, con objetividad y criterio técnico-jurídico, los conflictos electorales.

La autonomía de esos jueces supone, ante todo, estar únicamente sometidos a las normas jurídicas al momento de sentenciar las causas.

Si bien el principio autonómico no es necesariamente incompatible con la previsión de medios de impugnación contra lo resuelto por la jurisdicción electoral, se garantiza "una mayor independencia funcional, al no dejar tales decisiones sujetas a revisiones ni modificaciones por parte de ningún otro órgano" (IDEA, 2011, p. 22).

Con la convicción que lo caracterizaba, nos decía Urruty (2007, p. 15) que, "aun cuando se establezca a texto expreso que el organismo electoral es el competente para decidir en materia electoral, la realidad indica que el verdadero órgano supremo, que termina resolviendo la contienda electoral, es el llamado a resolver el recurso". Y es lo cierto que, con la habilitación para impugnarla, la decisión electoral se torna frágil y provisional, dado que solo se consolida cuando logre atravesar el tamiz de jueces no especializados.

En ese orden de consideraciones, luce contradictoria con el proceso de especialización y autonomía de los jueces electorales la posibilidad, aún vigente en varios ordenamientos regionales, de que tribunales de otro tipo revisen las resoluciones de los electorales. Según lo apuntaba en otra ocasión, esto se justificaría en la etapa de transición del contencioso político al contencioso judicializado, pero, en el estado actual de evolución, está plenamente justificado que la jurisdicción electoral resuelva en forma terminal los conflictos propios de su competencia (Sobrado, 2010, pp. 36-37).

Con independencia de estas consideraciones de lege ferenda, me atrevo a postular, como máxima hermenéutica que debería respetarse, el imperativo de intepretar restrictivamente las normas que autoricen esas intervenciones revisoras. Ello deriva, a mi juicio, de que la electoral no es solamente una jurisdicción especializada. Goza, además, de rango constitucional y opera como garantía institucional de la vigencia democrática, lo que le confiere una singular relevancia, así como preminencia sobre jueces de otra naturaleza. Esto se refuerza en un país como el mío, en donde la justicia electoral la imparten magistrados que encabezan un órgano con el rango e independencia de poder estatal; condición que ni siquiera la jurisdicción 


\section{DERECHO ELECTORAL}

constitucional, que está a cargo de una sala de la Corte Suprema de Justicia, ostenta.

\section{LA COMPLEJA CONVIVENCIA DE LAS JURISDICCIONES CONSTITUCIONAL Y ELECTORAL}

Decía en un trabajo anterior que el deslinde de competencias entre la jurisdicción electoral y la constitucional no resulta conceptualmente fácil y es motivo frecuente de conflictos y de debates académicos recurrentes.

No es extraño observar que la autonomía de los jueces electorales latinoamericanos suele estar matizada por la capacidad de los tribunales, cortes o salas constitucionales de incidir en la materia electoral. En algunos casos, la jurisprudencia y aun las decisiones concretas de aquellos son revisables por estos; en otros, la jurisdicción constitucional se considera competente para conocer, por la vía del recurso de amparo, de acciones u omisiones que afecten derechos fundamentales de carácter político, aunque tengan relación directa con lo electoral (cuando, por ejemplo, provengan de un partido político); y, en casi todos los ordenamientos que interesan, los jueces constitucionales son los únicos llamados a valorar la constitucionalidad del ordenamiento electoral, incluidas las normas de los estatutos partidarios.

Sin embargo, la maduración de una auténtica y confiable jurisdicción electoral latinoamericana lleva naturalmente aparejada una paulatina desaparición de ese tutelaje y la plena afirmación del carácter exclusivo y excluyente de sus potestades, aun frente a la jurisdicción constitucional. Esto conduce a entender, en primer lugar, que las sentencias dictadas a propósito del contencioso electoral deberían, en todos los supuestos, resultar inmunes al control de los jueces constitucionales; $y$, en segundo lugar, que cualquier reclamo o conflicto dotado de electoralidad, inclusive si media la afectación de derechos políticos, habría de canalizarse a través del contencioso electoral y no de los procedimientos usuales de la jurisdicción constitucional de la libertad, salvo que el propio juez electoral decline su competencia. Finalmente, ante la declaración que hacen algunas constituciones del área, en el sentido de que la interpretación de la normativa electoral compete privativamente al tribunal electoral, es defendible la tesis según la cual el control de la constitucionalidad de las leyes y demás normas electorales únicamente debería estar a cargo de ese mismo tribunal. 


\section{DERECHO ELECTORAL}

En esa oportunidad agregaba que desembarazar al contencioso electoral de una ulterior revisión de lo decidido ante el tribunal, corte o sala constitucional de aquellos países que así lo prevén, contribuye también a racionalizar las instancias recursivas y de esa manera a una justicia electoral más expedita. Esto, que es una característica esperable de cualquier forma de administración de justicia, tiene una singular importancia tratándose de la electoral, porque la pronta resolución de los litigios condiciona la declaratoria de elección respectiva que, de no darse oportunamente, provoca un vacío de autoridad gubernamental de incalculables consecuencias (Sobrado, 2006, pp. 171-172).

Esta posible evolución normativa no se ha concretado en América Latina ni figura en las actuales agendas de reforma electoral. A ello se agrega que, durante la década en curso, los tribunales constitucionales centroamericanos no solo no hacen suya la prudente regla hermenéutica que postulaba líneas atrás, sino que se evidencia en ellos una clara tendencia invasiva respecto de competencias expresamente tasadas como exclusivas y excluyentes de los tribunales electorales.

Tengamos presente, a modo de ejemplo, que la jurisdicción constitucional anuló una sentencia interpretativa del organismo electoral, así como algunas de sus determinaciones respecto de la realización de referendos (Costa Rica). Que dejó sin efecto órdenes de suspensión de propaganda política irregular (Panamá). Que impuso reescrutinios y decidió sobre la cancelación del registro de partidos políticos (El Salvador). Y que forzó la inscripción de candidaturas inviables, a través de sentencias de una cuestionada fundamentación, que anularon normas incluso de jerarquía constitucional (Honduras).

Pero este fenómeno tiende a expandirse más allá de las fronteras centroamericanas. Lo ilustra el caso peruano, en donde la justicia constitucional afirmó su competencia para controlar las actuaciones del Jurado Nacional de Elecciones, en detrimento de la disposición del Código Procesal Constitucional que impedía esa revisión. Más recientemente, el embate lo sufrió el Tribunal Superior Electoral de la República Dominicana. Decisiones suyas, en torno al proceso de renovación de las estructuras internas de un partido y a modificaciones estatutarias, fueron revocadas por los jueces constitucionales, a pesar de que la propia Constitución del país señala que compete a ese Tribunal Superior "juzgar y decidir con carácter definitivo sobre los asuntos contencioso electorales y estatuir sobre los 


\section{DERECHO ELECTORAL}

diferendos que surjan a lo interno de los partidos, agrupaciones y movimientos políticos o entre éstos".

\section{APUNTES PRELIMINARES SOBRe EL CASO COSTARRICENSE}

El Tribunal Supremo de Elecciones de Costa Rica (TSE) surgió con la Constitución Política de 1949 bajo la fórmula unificada. Su adecuado diseño y su exitoso desempeño ha sido un factor importante para la consolidación de la democracia más longeva y estable de América Latina.

Una de las claves de ese éxito fue la decisión constituyente de establecer, a texto expreso, el principio de "Autonomía de la función electoral" (art. 95.1), entendida como la "organización, dirección y vigilancia de los actos relativos al sufragio" y que se encarga al TSE para que la ejerza con "independencia" (art. 99). Esa autonomía se rodeó de una serie de excepcionales garantías. Para los efectos de esta exposición, me concentraré en la estipulada en el artículo 103 constitucional, que declara que sus resoluciones "no tienen recurso".

A nivel legal, ese principio se concretó, en primer lugar, excluyendo a los actos electorales del control de legalidad contencioso-administrativo, al prevérsele únicamente respecto del ejercicio (instrumental) de función administrativa por parte del TSE (art. 1 del Código Procesal Contenciosoadministrativo). $Y$, en segundo lugar, declarando legalmente improcedentes los recursos de amparo y las acciones de inconstitucionalidad que se intentaran contra los actos y disposiciones del TSE en materia electoral (arts. 30.d y 74 de la Ley de la Jurisdicción Constitucional).

Sobre la base de esas disposiciones y en una sentencia cercana a su creación (n.0 3194-92), la Sala Constitucional de la Corte Suprema de Justicia delimitó el ámbito de actuación del TSE que resulta inimpugnable ante ella: sus actos subjetivos, reglamentos y resoluciones jurisdiccionales propios de la esfera electoral, así como la interpretación normativa involucrada en esas actuaciones. Son revisables, en cambio, los actos del TSE de naturaleza registral y los relativos al discernimiento de la nacionalidad, como también -agregaría yo- los que supongan el ejercicio de función administrativa pura o instrumental. Por último, en esa oportunidad la Sala precisó que preserva su potestad de controlar la constitucionalidad de las normas electorales, lo que comprende las disposiciones no escritas que deriven de los precedentes y la jurisprudencia electoral. Sobre este 


\section{DERECHO ELECTORAL}

último punto, conviene aclarar que el TSE entiende (desde su sentencia n. ${ }^{\circ}$ 393-E-2000) que, con motivo de la tramitación de recursos de amparo electorales y por propia autoridad, puede -y debe- desaplicar para el caso concreto normas partidarias contrarias a la Constitución, sin perjuicio de que estas puedan ser posteriormente conocidas, en una perspectiva de anulación general y definitiva, por la Sala.

Similar relevancia tuvo la sentencia n. ${ }^{\circ}$ 2150-92 de la Sala Constitucional, al determinar que corresponde al TSE arbitrar los conflictos electorales, incluyendo los suscitados dentro de los partidos; y que solo en los casos en que el TSE decline su competencia natural se abre la de la Sala para conocer sobre el particular, si media la lesión a derechos fundamentales.

La claridad y vigencia por dos décadas de estos hitos jurisprudenciales de 1992, desproblematizaron la cuestión, facilitaron la expansión de la competencia jurisdiccional del TSE (positivada en el Código Electoral de 2009) y preservaron satisfactoriamente su autonomía (Sobrado, 2011, p. 256). Estas y otras resoluciones posteriores de ambos tribunales supusieron un fecundo diálogo interjurisdiccional con el que, "con gran madurez y respeto" (según palabras de la Sala Constitucional), se fueron reduciendo las zonas grises y se precisaron de mejor manera sus fronteras competenciales (Sobrado, 2011, p. 254). Diálogo presidido por una sana autocontención de ambas partes, en procura de preservar los equilibrios y no debilitar la autoridad superior de dos instituciones clave en la promoción de la democracia y en la defensa de la Constitución y de los derechos fundamentales.

No obstante, paralelamente a la renovación generacional de la Sala Constitucional, este cuadro empieza a resquebrajarse en el año 2010. A partir de ese momento, se ha estado replanteando ese balance. Aunque sus resoluciones denotan posiciones oscilantes, por la fragilidad de las mayorías que las sustentan, sin duda predomina el activismo judicial de la tesis "revisionista".

En esa línea, ya mencionamos dos precedentes: la anulación de resoluciones del TSE en materia de referéndum (a partir del voto n. ${ }^{\circ} 2010-13313$ ) y de una sentencia suya de carácter interpretativo (voto n.0 2015-16070). Ahora me concentraré en lo resuelto por la Sala bajo el voto n. ${ }^{\circ}$ 2014-17833 que sostuvo que las sentencias del TSE que anulan o cancelan credenciales de funcionarios de elección popular son discutibles ante la jurisdicción contencioso-administrativa; posición que también expuso la Sala Primera 


\section{DERECHO ELECTORAL}

de la misma Corte Suprema de Justicia (encargada de conocer la casación en materia contencioso-administrativa, civil y agraria) en su voto n. ${ }^{\circ}$ $000800-C-S 1-2014$.

Esa última resolución de la Constitucional, cuya parte considerativa fue comunicada casi treinta y un meses después de adoptada, justifica lo así definido alegando que anular o cancelar credenciales es una actividad típicamente administrativa y no electoral, aunque sea dispuesto por el TSE y esté legalmente incorporado a la justicia electoral.

Para poder confrontar adecuadamente esa definición, debo examinar antes los dilemas que plantea el principio de irrecurribilidad cuando se trata de organismos electorales unificados, como lo es el TSE.

\section{PRINCIPIO DE IRRECURRIBILIDAD Y FóRMULA UNIFICADA}

La fórmula unificada de organización electoral que siguen algunos países latinoamericanos tiene obvias ventajas. Abona, por ejemplo, la eficiencia de la gestión institucional y evita el clima de conflictividad endémica que caracteriza a algunos organismos electorales diversificados.

Sin embargo, es también de reconocer que se aleja de la ortodoxia del principio de división de poderes. Ya el Barón de Montesquieu, en El espíritu de las leyes, nos advertía:

no hay libertad, si la potestad de juzgar no está separada de la potestad legislativa y de la ejecutiva. Si estuviese unida a la potestad legislativa, el poder sobre la vida y la libertad de los ciudadanos sería arbitrario, debido a que el juez sería el legislador. Si se uniera a la potestad ejecutiva, el juez podría tener la fuerza de un opresor". (Libro XI, capítulo 6).

Es lo cierto que si los mismos funcionarios que administran las elecciones son quienes, simultáneamente, imparten justicia electoral, se crea una zona de inmunidad al control jurídico de los respectivos actos de administración electoral. Situación que, como aconteció en el caso "Yatama vs. Nicaragua", abre las puertas para reprochar la vulneración de la Convención Americana sobre Derechos Humanos que prescribe el derecho de toda persona a "un recurso sencillo y rápido o a cualquier otro recurso efectivo ante los jueces o tribunales competentes, que la ampare contra actos que violen sus derechos fundamentales reconocidos por la Constitución, la ley o la 


\section{DERECHO ELECTORAL}

presente Convención, aún cuando tal violación sea cometida por personas que actúen en ejercicio de sus funciones oficiales" (art. 25).

Soy de la opinión que la manera sabia de afrontar ese dilema no es hacer implosionar la fórmula unificada ni sacrificar el principio de irrecurribilidad, por lo menos en aquellas latitudes donde ha funcionado adecuadamente y forma parte de una provechosa tradición jurídico-política. De lo que se trata es de encontrar mecanismos inteligentes de reingeniería institucional que, manteniendo las fortalezas de esta fórmula, atiendan ese legítimo reproche.

Uno de esos mecanismos lo exploró precisamente la República Dominicana, dividiendo su Junta Central Electoral en dos Cámaras (Administrativa y Contenciosa); solución que, empero, resultó fallida y el país finalmente migró a la fórmula diversificada.

Otro ejemplo lo proporciona justamente Costa Rica, a partir de la creación del Registro Electoral con la promulgación en 2009 del Código Electoral vigente. Este Registro pasó a ser la instancia fundamental de administración electoral, responsable directo de las decisiones susceptibles de afectar los derechos e intereses concretos de los actores de los comicios (inscripción de partidos y candidatos, gestión de los programas electorales, fiscalización del financiamiento de las agrupaciones políticas, imposición de multas por faltas electorales, etc.).

Ciertamente, los magistrados electorales conservaron su rol de dirección superior, incluyendo la potestad de reglamentar la función electoral. No obstante, quedaron perfilados, ante todo, como jueces especializados que imparten justicia electoral en forma concentrada y "de manera exclusiva y excluyente" (art. 219 del Código Electoral), por intermedio de procesos que disciplina ese mismo cuerpo legal y que desembocan en sentencias dotadas de autoridad de cosa juzgada material. Sentencias que carecen de recurso y de la posibilidad de su revisión judicial ulterior; sin embargo, puede gestionarse su adición o aclaración, dentro del plazo de tres días luego de comunicada la sentencia (art. 223 del Código Electoral).

La justicia electoral costarricense comprende distintos procesos, que podemos distinguir y agrupar del siguiente modo:

a) Recurso de amparo electoral: sirve para tutelar los derechos fundamentales de naturaleza político-electoral, en especial (aunque 


\section{DERECHO ELECTORAL}

no exclusivamente) cuando los vulneren o amenacen los partidos políticos.

b) Contencioso electoral en sentido estricto: se refiere a la demanda de nulidad (vinculada con los resultados electorales y la aptitud legal de los candidatos virtualmente electos) y al recurso de apelación electoral (como control de legalidad de cualquier acto de la administración electoral o de agentes externos con atribuciones en la materia).

c) Acción de nulidad de acuerdos partidarios: también consiste en un control de legalidad, desplegado en este caso respecto de las actuaciones partidarias relacionadas con los procesos internos de selección de autoridades y de postulación de candidatos a cargos de elección popular.

d) Procesos sancionatorios: se trata de la resolución de denuncias por beligerancia política de los funcionarios públicos, así como de la cancelación o anulación de las credenciales de aquellos que son de elección popular.

Según lo explico en un texto recientemente publicado (Sobrado, 2018), los primeros tres de esos procesos jurisdiccionales tienen, como característica compartida, el ser mecanismos de revisión, a cargo de los magistrados electorales, de lo actuado u omitido por la administración electoral inferior, los partidos políticos u otros sujetos.

En cambio, los de beligerancia política y cancelación o anulación de credenciales se distinguen por ser procesos de naturaleza sancionatoria en los que, independientemente de quien denuncia o insta la intervención jurisdiccional, el juez electoral impone un castigo al trasgresor, sea, adopta directamente una decisión que afecta a una o varias personas en particular.

Esto planteaba el dilema de entender que las sentencias del TSE en este ámbito sancionatorio sí resultaban revisables en la órbita judicial (contradiciendo el mandato de irrecurribilidad del artículo 103 constitucional) o pasar por alto el ya citado numeral 25 de la Convención Americana sobre Derechos Humanos (al negarse el derecho a recurrir un acto de gravamen).

Por otro lado, el TSE era consciente de que, como parte del control de convencionalidad que deben aplicar los órganos que administran justicia, es 


\section{DERECHO EIECTORAL}

necesario armonizar el ordenamiento interno con el derecho internacional de los derechos humanos (entre otros, véanse las consideraciones de los fallos de la Corte Interamericana de Derechos Humanos en los casos "Almonacid Arellano y otros vs. Chile" y "Trabajadores cesados del Congreso vs. Perú").

Una primera respuesta jurisprudencial que intentó superar este dilema fue reconocer, mediante la aplicación analógica del artículo 107 del Código Electoral, la posibilidad de que las resoluciones sancionatorias que dictara el TSE fueran susceptibles del recurso de reconsideración (sentencia n. ${ }^{\circ}$ 6290-E6-2011). Esa respuesta del año 2011 resultaba insuficiente a la luz del estándar de los derechos humanos, puesto que eran los mismos magistrados que sancionaban quienes, posteriormente, conocían del indicado recurso.

\section{ACCIÓN Y REACCIÓN}

Es en este contexto que la Sala Constitucional interpreta, en el indicado voto n. ${ }^{\circ}$ 2014-17833, que las resoluciones del TSE que cancelen credenciales de funcionarios de elección popular no son verdaderas sentencias electorales y resultan, por ello, debatibles en la jurisdicción contencioso-administrativa (al menos cuando se funden en la comisión de hechos constitutivos de acoso sexual); esto por cuanto, a su juicio, se trata de materia "típicamente administrativa, y no electoral" (así reiterado por la Sala en el voto n. ${ }^{\circ}$ 2017-20014).

Esta manera de ver las cosas es, desde mi punto de vista, equivocada. Supone, en primer término, restringir la competencia de la jurisdicción electoral mediante una visión estrecha de la materia electoral, en contradicción con una sólida doctrina de ambos tribunales, desarrollada desde el siglo anterior.

En efecto, la resolución del TSE n. 04 de las 9:25 horas del 3 de enero de 1996 ya apuntaba:

Por obvio que resulte, es preciso dejar claro que al decir la Constitución Política actos relativos al sufragio, dentro de la competencia atribuida al Tribunal, no sólo se comprenden los propios de la emisión del voto, sino todos aquellos descritos por la 


\section{DERECHO EIECTORAL}

propia Constitución o en las leyes electorales y que, directa o indirectamente se relacionen con todo el proceso electoral.

Días después se agregaba:

La naturaleza jurídica de la credencial y el manejo que de ella hace constitucional y legalmente el Tribunal antes y durante su entrega al funcionario electo, pudiendo incluso no hacerlo en los casos expresamente señalados, constituyen elementos indicadores de una competencia implícita para cancelarla con posterioridad, cuando su titular viole las prohibiciones establecidas en la propia Constitución bajo pena de perderla ... Por estas razones, no deben ser extraños al derecho electoral los hechos posteriores al sufragio atribuidos a un diputado o a otro funcionario de elección popular y que la propia Constitución sancione con la pérdida de su credencial. (Resolución n. 0 38-96 de las 9 horas del 10 de enero de 1996).

En absoluta concordancia, la sentencia de la Sala Constitucional n. ${ }^{0}$ 2000-6326 señalaba que:

...la actividad electoral comprende las de organizar, dirigir y fiscalizar todos los actos relativos con el proceso de elecciones nacionales (sentencia número 0653-98), la cual se desarrolla en actividades tales como las siguientes: la regulación de las normas que rigen la deuda política, así como el control que sobre esta materia tiene el Tribunal Supremo de Elecciones (0980-91, 366693, 0515-94, 0428-98); el control de las regulaciones estatutarias relativas al derecho de elegir y ser elegido en los procesos internos de los partidos políticos (sentencia número 3294-92); la integración del Concejo Municipal, la declaratoria de la elección y las posteriores sustituciones por pérdidas de credenciales de los regidores y síndicos municipales (sentencia número 2430-94); la tramitación del proceso contencioso electoral para conocer de la cancelación o anulación de credenciales de regidores municipales (sentencia número 0034-98); ... y la determinación por parte del Tribunal Supremo de Elecciones de donde realizará la celebración solemne el día de las elecciones, para el conteo inicial de los resultados de las elecciones nacionales (0563-98). [Subrayado no es del original]. 


\section{DERECHO ELECTORAL}

En segundo término, estimo que el criterio sentado por la Sala a partir de 2014 es erróneo también por desconocer el expreso encuadre legislativo de este tipo de asuntos como jurisdiccionales y no en el campo del derecho administrativo sancionador. Nótese que la Constitución no impone considerar el ejercicio del ius puniendi estatal únicamente dentro de la esfera administrativa (lo que conllevaría el absurdo de estimar como inconstitucional la existencia de la jurisdicción penal), sino que lo deja al prudente arbitrio de la representación popular.

Pero lo más grave es que, al perfilar como administrativa -y no jurisdiccional- la intervención del TSE en los procesos sancionatorios en general, innecesariamente la Sala provoca una situación contradictoria con el precedente establecido en el 2011 por la Corte Interamericana de Derechos Humanos, caso "López Mendoza vs. Venezuela", que demanda la intervención de un juez para poder suprimir o suspender el derecho al sufragio pasivo. Y ello está involucrado en los procesos de beligerancia política, que constitucionalmente está sancionada con la destitución del responsable y su inhabilitación para ejercer cargos públicos por no menos de dos años (art. 102.5).

En el fondo de la cuestión está la circunstancia de que la Sala no considera el sentido último de involucrar al TSE en estos procesos sancionatorios. No es otro que el de privar a la administración (Contraloría General de la República, concejos municipales o cualquier otra instancia) de la autoridad para hacer decaer anticipadamente el mandato popular del electo. Esa posibilidad se reserva constitucionalmente al juez electoral, cuya figuración lo es a título de garantía y en protección del sufragio que generó el vínculo representativo.

En esta coyuntura, el TSE reaccionó reivindicando lo que entiende es su espacio de actuación autónoma como juez especializado. La defensa de su independencia frente al Poder Judicial en general, garantizada constitucionalmente, la emprendió con sobriedad y sin escándalo público, pero sí de manera clara, precisa y contundente.

Esa defensa se formalizó, especialmente, con el dictado del decreto n. ${ }^{\circ}$ 5-2016 del 2 de junio del 2016, por cuyo intermedio se promulgó el "Reglamento de la Sección Especializada del Tribunal Supremo de Elecciones que tramita y resuelve en primera instancia asuntos contenciosos-electorales de carácter sancionatorio" (RSE). 


\section{DERECHO ELECTORAL}

Sus considerandos confrontan la posición de la Sala al indicar expresamente que, en virtud del principio constitucional de irrecurribilidad de sus disposiciones electorales, las sentencias de la justicia electoral no pueden ser discutidas en sede judicial. En una ocasión posterior, el TSE aclaró que un juicio contencioso-administrativo solo cabría en orden a fijar responsabilidades por lo previamente resuelto, pero sin posibilidad de revertir la decisión electoral propiamente dicha.

El decreto también fundamenta la creación de la Sección Especializada a partir de un examen de convencionalidad de las reglas procesales, en procura de armonizarlas con la garantía prevista en el numeral 25 del Pacto de San José.

La Sección Especializada está integrada por tres magistrados suplentes que se renuevan semestralmente (arts. 2 y 3 ); sus sentencias son impugnables (por intermedio del recurso de reconsideración) ante el pleno propietario (arts. 11 y 14, RSE). Es decir, compete a esa Sección resolver los procesos sancionatorios en general y por las vías procesales ordinarias, pero dejando al margen a los magistrados propietarios, quienes posteriormente podrían conocer del asunto en fase recursiva. Con ello, las decisiones definitivas se mantienen dentro de los linderos de la jurisdicción electoral, pero otorgando a las partes un "recurso ágil y sencillo" que ampare sus derechos y garantizando que este sea conocido por jueces que no hayan adelantado su criterio sobre la cuestión justiciable. En suma: procesos sancionatorios que, sin salir de la órbita del TSE, se articulan en dos instancias, para conciliar así la regla constitucional de irrecurribilidad (externa) y el derecho reconocido en la Convención Americana sobre Derechos Humanos.

\section{RefleXión final}

Iniciamos este trabajo con Newton, utilizando como metáfora descriptiva su tercera ley del movimiento. Quiero terminarlo recurriendo a la primera de esas leyes, la de la inercia, que plantea que todo cuerpo permanece en su estado de reposo o movimiento uniforme, a menos que sobre él actúe una fuerza externa.

Esta ley nos brinda, también metafóricamente, un valioso recordatorio: que la problemática que aqueja a los jueces electorales de la región no se resuelve por sí sola. Si no nos ocupamos de ella, si no le atravesamos nuestros cuerpos, inercialmente continuará y podría incluso agravarse. No 


\section{DERECHO EIECTORAL}

nos perdonaríamos, a la larga, que nos mantengamos impasibles viendo cómo se siguen corriendo los mojones y se estrecha nuestro fundo competencial, desdibujándose el rol que juramos desempeñar.

No estoy sugiriendo, aclaro, llamar a una bochornosa guerra santa entre jueces. Más bien propongo no esconder la basura debajo de la alfombra, sino afrontar asertivamente la cuestión. Con respeto, pero también firmeza.

Esto significa hacernos oír fomentando el debate dentro y fuera de la academia, cosechando aliados de camino, sensibilizando a nuestros pueblos del papel crucial que nos encomendaron y ejerciendo, con valentía y creatividad, el espacio de actuación autónoma que las constituciones nos ofrecen y garantizan, aun frente a la jurisdicción constitucional.

La realidad de cada país de América Latina impone un distinto sentido de urgencia y aconseja cursos de acción diversos. Corresponde a cada uno de nosotros determinarlos con sabiduría.

Sea cual fuere el escenario particular que enfrentemos, nunca hemos de olvidar la pertinencia que en democracia tiene el diálogo, como forma civilizada para intentar persuadir y como base que es de una convivencia armónica. La verdad es que los jueces de uno y otro lado no debemos vernos como adversarios; nos une, como aliados, la causa común de la preservación y el fortalecimiento del Estado constitucional y democrático de derecho, que el siglo XXI latinoamericano somete a viejas y nuevas acechanzas. Debemos acercarnos para permitir que aflore la natural empatía entre sus mejores guardianes, luego de compartir con franqueza nuestras justificadas preocupaciones.

Esa empatía consolidaría un esfuerzo responsable y compartido para zanjar el desencuentro; esfuerzo que debe aprovechar cada oportunidad que se presente para tender puentes de plata 


\section{DERECHO ELECTORAL}

\section{Referencias bibliográficas}

Costa Rica (1949). Constitución Política del 7 de noviembre.

Costa Rica (2006). Código Procesal Contencioso Administrativo del 24 de abril.

Costa Rica (2009). Código Electoral, ley n. ${ }^{\circ} 8765$ del 19 de agosto de 2009, publicado en alcance n. ${ }^{\circ} 37$ a La Gaceta n. ${ }^{\circ} 171$ del 2 de setiembre.

IDEA Internacional. (2011). Justicia electoral: una introducción al manual de IDEA Internacional. Estocolmo: IDEA.

Nohlen, D. (2017). Sistemas electorales y jurisdicción constitucional en América Latina. Algunas experiencias comparadas. Política y Gobernanza. Revista de Investigaciones y Análisis Político, 1, 5-29.

Orozco, J.(2001). Sistemas de justicia electoral en el derecho comparado. Sistemas de justicia electoral: evaluación y perspectivas. México: IFE-PNUDUNAM-IFES-IDEA-TEPJF, pp. 45-58.

Picado, H. y Aguilar, I. (2012). La formación en democracia: nueva tendencia en los organismos electorales latinoamericanos. Revista de Derecho Electoral, (14), 116-141.

Sobrado, L. A. (2011). El deslinde competencial entre el Tribunal Supremo de Elecciones y la Sala Constitucional: una historia inconclusa en cuatro capítulos. Revista de Derecho Electoral, (12), 249-260.

Sobrado, L. A. (2008). Los organismos electorales: autonomía, formación electoral y democracia. Revista de Derecho Electoral, (6), 19-31.

Sobrado, L. A. (2010). Nuevos desafíos de la justicia electoral: la expansión de los derechos políticos y la promoción de la democracia interna de los partidos políticos. Revista de Derecho Electoral, (10), 35-44.

Sobrado, L. A. (2018). Para entender el Tribunal Supremo de Elecciones y la justicia electoral, San José: IFED/KAS.

Sobrado, L. A. (2006). Tendencias de la justicia electoral latinoamericana y sus desafíos democráticos. Revista de Ciencias Jurídicas, (109), 155-183.

Urruty, C. (2007). La importancia de los organismos electorales. Revista de Derecho Electoral, (3), 5-21. 


\section{DERECHO EIECTORAL}

\section{Resoluciones}

Corte Interamericana de Derechos Humanos (2005). Caso Yatama vs. Nicaragua, sentencia del 23 de junio.

Sala Constitucional de la Corte Suprema de Justicia de Costa Rica (1992). Sentencia n. ${ }^{\circ}$ 3194-92 de las dieciséis horas el veintisiete de octubre.

Sala Constitucional de la Corte Suprema de Justicia de Costa Rica (1992). Sentencia n. ${ }^{\circ} 2150-92$ de las doce horas del ocho de agosto.

Sala Constitucional de la Corte Suprema de Justicia de Costa Rica (2000). Sentencia 2000-6326 de las dieciséis horas con dieciocho minutos del diecinueve de julio

Sala Constitucional de la Corte Suprema de Justicia de Costa Rica (2010). Sentencia 2010-13313 de las dieciséis horas con 31 minutos del 10 de agosto.

Sala Constitucional de la Corte Suprema de Justicia de Costa Rica (2014). Sentencia 2014-17833 de las dieciséis horas veinte minutos del veintinueve de octubre.

Sala Constitucional de la Corte Suprema de Justicia de Costa Rica (2014). Sentencia 2014-17833 de las dieciséis horas veinte minutos del veintinueve de octubre.

Sala Constitucional de la Corte Suprema de Justicia de Costa Rica (2015). Sentencia 2015-16070 de las once horas con treinta y un minutos del catorce de octubre

Sala Constitucional de la Corte Suprema de Justicia de Costa Rica (2017). Sentencia 2017-20014 de las once horas y cuarenta minutos del doce de diciembre.

Sala de Casación de la Corte Suprema de Justicia de Costa Rica (2014). Sentencia 000800-C-S1-2014 de las diez horas veinte minutos del diecinueve de junio.

Tribunal Supremo de Elecciones de Costa Rica (1996). Resolución 04-96 de las nueve horas y veinticinco minutos del tres de enero.

Tribunal Supremo de Elecciones de Costa Rica (1996). Resolución 038-96 de las nueve horas del diez de enero. 